\title{
In Vitro Comparison of Multinucleated Giant Cell Formation from Human Umbilical Cord and Adult Peripheral Blood Mononuclear Phagocytes
}

\author{
KARLA GERBERDING AND MERVIN C. YODER \\ Divisions of Pediatric Pulmonology [K.G.] and Neonatal-Perinatal Medicine and Herman B. Wells Center for \\ Pediatric Research [M.C.Y.], Indiana University School of Medicine, Indianapolis, Indiana 46202
}

\begin{abstract}
The fetus and newborn infant are highly susceptible to infection by pathogens that are capable of intracellular survival. The invasion of these microbes usually stimulates a granulomatous host defense response in the fetus or neonate. Multinucleated giant cells (MGC) are the predominant cells composing the granuloma and represent the terminally differentiated state of activated macrophages. Because macrophages derived from human umbilical cord blood monocytes demonstrate some deficiencies in activated functions, we tested the ability of these cells to form MGC in vitro. Mononuclear cells from umbilical cord blood and adult peripheral blood were isolated and cultured for 7,14 , or $21 \mathrm{~d}$ before stimulation with phorbol myristate acetate (PMA), an agent known to stimulate MGC from mononuclear phagocytes in vitro. Spontaneous MGC formation occurred in both cord and adult blood mononuclear cell cultures by $\mathrm{d} 7$ of incubation, although significantly fewer MGC formed in the cord blood cultures. PMA treatment of adult blood mononuclear cells resulted in a significant increase in MGC formation after 7, 14, or $21 \mathrm{~d}$ of culture, but PMA did not significantly increase MGC formation in cord blood cultures until 14 or $21 \mathrm{~d}$ of culture. Pretreatment of cord and adult blood mononuclear cells with 1,25 -dihydroxyvitamin $\mathrm{D}_{3}$ inhibited PMA-induced MGC formation. However, when a purified population of cord blood, monocyte-derived macrophages were pretreated with 1,25-dihydroxyvitamin $\mathrm{D}_{3}$, PMA significantly increased MGC formation. These data indicate that distinct differences exist between mononuclear phagocytes isolated from cord blood versus adult peripheral blood with respect to in vitro MGC formation and that a unique population of 1,25-dihydroxyvitamin $\mathrm{D}_{3}$-responsive macrophages is derived from cord blood monocytes. (Pediatr Res 33: 19-26, 1993)
\end{abstract}

Abbreviations

MGC, multinucleated giant cell

$1,25(\mathrm{OH})_{2} \mathrm{D}_{3}, 1,25$-dihydroxyvitamin $\mathrm{D}_{3}$

PMA, phorbol myristate acetate

HG, 1-0 hexadecyl 1-2-0 acetyl glycerol

GM-CSF, granulocyte-macrophage colony-stimulating factor

The human fetus and newborn infant are at high risk of developing systemic bacterial, viral, and other microbial infections. Pathogens capable of surviving intracellularly in phagocytes (e.g. Toxoplasma, Listeria, herpes simplex virus, and cytomegalovirus) require the host to mount a cell-mediated immune

Received June 1, 1992.; accepted September 2, 1992.

Correspondence: Dr. Mervin C. Yoder, Herman B. Wells Center for Pediatric Research, 702 Barnhill Drive, Room 2612, Indianapolis, IN 46202-5210.

Supported in part by Cystic Fibrosis Foundation Grant D0270-1. response for adequate protection (1). Such responses are slow to develop and often ineffectual in the neonate, partly because of poor mobilization of nonspecific phagocytic defenses and diminished production of cytokines by mononuclear cells.

Granulomatous inflammatory responses are an attempt by the host to sequester and gradually eliminate persistent infectious agents, including the above-listed pathogens, or nondegradable material from the body (2-4). In the case of infectious organisms, granulomatous lesions begin as a cell-mediated reaction with $\mathrm{T}$ lymphocyte and mononuclear phagocyte participation. In time, activated macrophages become the predominant cell type of the granuloma. These macrophages frequently fuse into MGC, the terminally differentiated form of activated macrophages (5). MGC formation remains poorly understood, although certain nondegradable microparticles (6) and soluble agents such as PMA, interleukins-3 and -6 , interferon- $\gamma$, retinoic acid, GMCSF, mitogen-stimulated lymphocyte-conditioned media, and $1,25(\mathrm{OH})_{2} \mathrm{D}_{3}$ promote mononuclear phagocyte fusion into MGC in vitro $(7-12)$.

In light of the documented impairments in activation of cord blood mononuclear phagocytes (13), we examined the ability of neonatal cord blood mononuclear phagocytes to form MGC in vitro. Induction of $\mathrm{MGC}$ formation by exposure to agents known to stimulate macrophage fusion [PMA, $1,25(\mathrm{OH})_{2} \mathrm{D}_{3}$ ] was compared using neonatal cord blood and adult human peripheral blood mononuclear cells. Distinct differences are reported in spontaneous MGC formation and in macrophage fusion in the presence of $1,25(\mathrm{OH})_{2} \mathrm{D}_{3}$ and PMA when comparing cells isolated from newborn cord blood versus adult human peripheral blood.

\section{MATERIALS AND METHODS}

Cell isolation and culture. These studies were reviewed and approved by the Indiana University Institutional Review Board for the Protection of Human Subjects. Blood was collected from the cut end of the umbilical cord from normal-term newborn infants or from peripheral veins of normal, healthy 25 - to 30 -yrold male adult volunteers into sterile heparinized $(20-\mathrm{U} / \mathrm{mL})$ syringes. The suspended cells were layered over Histopaque 1077 (Sigma Chemical Co., St. Louis, MO), and mononuclear cells were isolated by density centrifugation (14). Isolated mononuclear cells were cultured in DMEF-12 media (Sigma) containing 0.10 human $\mathrm{AB}$ serum at a density of $1 \times 10^{6}$ cells $/ \mathrm{mL}$ in $24-$ well culture plates on sterilized glass coverslips. Cultures were incubated in a $5 \% \mathrm{CO}_{2}$ humidified environment at $37^{\circ} \mathrm{C}$. Cultures were fed every $4 \mathrm{~d}$ by carefully removing one half of the conditioned media and replacing it with fresh media.

In some experiments, monocytes were isolated from other mononuclear cells by allowing the mononuclear cells to adhere to gelatin-coated flasks for $1 \mathrm{~h}$ at $37^{\circ} \mathrm{C}$ (14). Nonadherent cells were removed by washing the flasks with media three times. 
Adherent cells were removed by adding media with EDTA (5 $\mathrm{mM}$ ) for 15 min followed by tapping the flask. Recovered cells were $>0.90$ monocytes as determined by myeloperoxidase staining, phagocytic activity, and cell-surface expression of CD11b as previously described $(14,15)$. In all experiments, by $7 \mathrm{~d}$ of culture, the adherent cells were $>0.95$ macrophages by morphology and by staining for $\alpha$-napthyl butyrate esterase and tartrateresistant acid phosphatase using commercial kits (Sigma). Furthermore, adherent cell viability (trypan blue exclusion $>0.95$ ) and cell numbers (cells counted in four randomly selected micrometer fields) in cultures of adult and cord blood mononuclear phagocytes were equivalent $\left(\sim 4.0 \times 10^{4}\right.$ cells/coverslip $)$.

Experimental protocol. On d 7, 14, or 21 of culture, PMA (Sigma), placebo (0.001 DMSO), or fresh medium was added to wells of cultured cells and the cells were incubated for an additional $16 \mathrm{~h}$. Preliminary experiments were performed to determine the optimal concentration of PMA (range, 1-100 nmol) that induced maximal MGC formation. Inhibition of PMAinduced MGC formation using a protein kinase C-specific inhibitor, $\mathrm{HG}$, was performed by concomitantly adding $\mathrm{HG}$ (Sigma) and PMA to the mononuclear cell cultures at 7, 14, or $21 \mathrm{~d}$ and culturing for $16 \mathrm{~h}$. Again, preliminary experiments were performed to determine the concentration of $\mathrm{HG}$ that maximally inhibited PMA-induced MGC formation. In some experiments, mononuclear cells or purified monocytes were pretreated with $1,25(\mathrm{OH})_{2} \mathrm{D}_{3}\left(10^{-8} \mathrm{~mol}\right)$ for $21 \mathrm{~d}$ (media replaced every $4 \mathrm{~d}$ ) before addition of PMA or placebo for an additional $16 \mathrm{~h}$.

In some experiments, cocultures of adherent and nonadherent mononuclear cells were initiated using 24-well culture plate inserts (Costar Corp., Cambridge, MA) to prevent the two populations of cells from physically interacting but to allow soluble agents released by each population to be freely diffusable. Thus, adult peripheral blood or cord blood nonadherent mononuclear cells ( $>0.90$ lymphocytes by morphology) were plated in culturewell inserts above coverslips of adherent adult peripheral blood or cord blood monocyte-derived macrophages.

At the completion of each experiment, coverslips were removed from the culture wells and washed, and adherent macrophages were stained with Wright's stain. The percentage of MGC formed was assessed in all experiments by counting a minimum of 600 cells per triplicate set of coverslips with an MGC defined as a cell with three or more nuclei (number MGC/ $600 \times 100=\% \mathrm{MGC})$. A fusion index (\%) was calculated as the number of nuclei present in the entire population of MGC divided by the total number of nuclei counted in the 600 -cell sample multiplied by 100 . The fusion index increases as the percentage of MGC formed increases, but the fusion index also reflects changes in the overall number of nuclei present in the MGC that may occur independent of changes in the percentage of MGC formed. Each experiment was performed in triplicate and repeated a minimum of three times.

Cell proliferation assay. Determination of cell proliferation was performed by immunocytochemical detection of 5-bromo2 '-deoxyuridine incorporation using a commercial kit (Amersham Corp., Arlington Heights, IL). Briefly, PMA-treated macrophages from mononuclear cell or monocyte-derived macrophage cultures were labeled by incubating the coverslips in 5bromo-2'-deoxyuridine for $60 \mathrm{~min}$. The coverslips were washed and adherent cells fixed in 0.95 ethanol- 0.5 acetic acid solution. The cells were rehydrated, and a murine MAb to 5-bromo-2'deoxyuridine was added for $1 \mathrm{~h}$. The labeled cells were washed, and peroxidase anti-mouse Ig antibody was added for a 30 -min incubation. Detection of the peroxidase-labeled antibody was achieved using diaminobenzidine in the presence of cobalt and nickel. Proliferating cells revealed blue-black nuclear staining and the percentage of dividing cells was counted from a minimum of 200 total cells. A human monocytic leukemia cell line THP-1 (American Type Culture Collection, Rockville, MD) served as a proliferating positive control. Uninduced THP-1 cells were treated as above and applied to glass slides by cytospin
(Shandon Southern Instruments, Inc., Pittsburgh, PA) while PMA-treated THP-1 cells readily adhered to glass coverslips present in the tissue culture plates.

Statistical analysis. Statistical analysis of data was performed using the unpaired or paired $t$ test with the level of significance set at $p<0.05$. All data are recorded as mean \pm SEM unless otherwise indicated.

\section{RESULTS}

In vitro culture of human mononuclear phagocytes derived from adult peripheral blood and cord blood mononuclear cells was associated with the appearance of mature macrophages, including some spontaneously developing MGC (Table 1). Treatment of mononuclear cells with 0.001 DMSO (placebo control for PMA experiments) did not influence the percentage of MGC formed or the fusion index in any of the experiments compared with untreated cultures (data not shown). Adherent macrophages derived from cord blood mononuclear cells appeared morphologically similar to macrophages derived from adult peripheral blood (Fig. 1), were equivalent in number, and $>0.95$ expressed the differentiated macrophage enzymes, nonspecific $\alpha$-napthyl butyrate esterase, and tartrate-resistant acid phosphatase (7-10). However, significantly fewer MGC spontaneously appeared in the cord blood mononuclear cell cultures by $\mathrm{d} 7$ of observation (Table 1). At later time points, d 14 and 21 of culture, the number and fusion index of spontaneously appearing MGC was not significantly different in macrophage monolayers derived from cord or adult blood mononuclear cells (Table 1). Coculture of adult mononuclear cells (culture plate insert compartment) with adherent cord blood monocyte-derived macrophages failed to significantly influence the percentage of MGC appearing by d 7 of culture compared with cord blood mononuclear cultures alone (mean 3.1 and $4.8 \%$ MGC formed, respectively). Similarly, coculture of cord blood mononuclear cells (insert compartment) with adherent adult peripheral blood monocyte-derived macrophages failed to alter the percentage of MGC present in the adult macrophage cultures at $\mathrm{d} 7$ (mean 8.3 and $10.0 \%$ MGC formed, respectively).

Treatment of 21-d mononuclear cell cultures with $50 \mathrm{nmol}$ PMA resulted in optimal MGC formation with little cellular toxicity ( $>0.95$ trypan blue exclusion) as compared with lower or higher concentrations of PMA that yielded lower MGC formation (1, 5, 10, and $25 \mathrm{nmol}$ PMA treatment resulted in $<0.10$ MGC) or induced cell toxicity (100 nmol PMA treatment resulted in $<0.60$ trypan blue exclusion). PMA treatment of $7-d-$ old mononuclear cell cultures had no effect on cord bloodderived cells but significantly increased MGC formation (Table 1) in adult peripheral blood cells compared with placebo-treated cells. Coculture of adult mononuclear cells with cord blood mononuclear cells did not result in increased MGC formation in the cord blood mononuclear cell cultures in response to PMA (mean 6.1 and $4.9 \%$ MGC formed, respectively). PMA treatment significantly increased the percentage of MGC formed and the fusion index (Table 1, Fig. 1) for mononuclear cells (cord- or adult blood-derived) cultured for 14 or $21 \mathrm{~d}$ compared with placebo treatment, and the percentage of MGC formed and the fusion index were not different for treated cells derived from cord blood or adult peripheral blood (Table 1). The distribution of the number of nuclei per MGC was not different for control or PMA-induced MGC derived from 21-d cord blood or adult peripheral blood mononuclear cell cultures (Figs. 2 and 3). Both Langhan's (nuclei located at the periphery of the cell) and foreign body-type (nuclei dispersed throughout the cytoplasm) MGC were seen in cord blood and adult peripheral blood cultures (Fig. 1).

Protein kinase $\mathrm{C}$ has previously been reported to be an important mediator of PMA-induced macrophage fusion (7). HG, a specific inhibitor of protein kinase C (16), inhibited PMA-induced MGC formation and the fusion index in a dose-dependent 
Table 1. Spontaneous, PMA-induced, and HG inhibition of PMA-induced MGC formation (\% of total adherent cells) and fusion index (FI; \% of total adherent cell nuclei present in MGC) from human umbilical cord and adult peripheral blood mononuclear cells cultured for 7,14 , or $21 \mathrm{~d}$

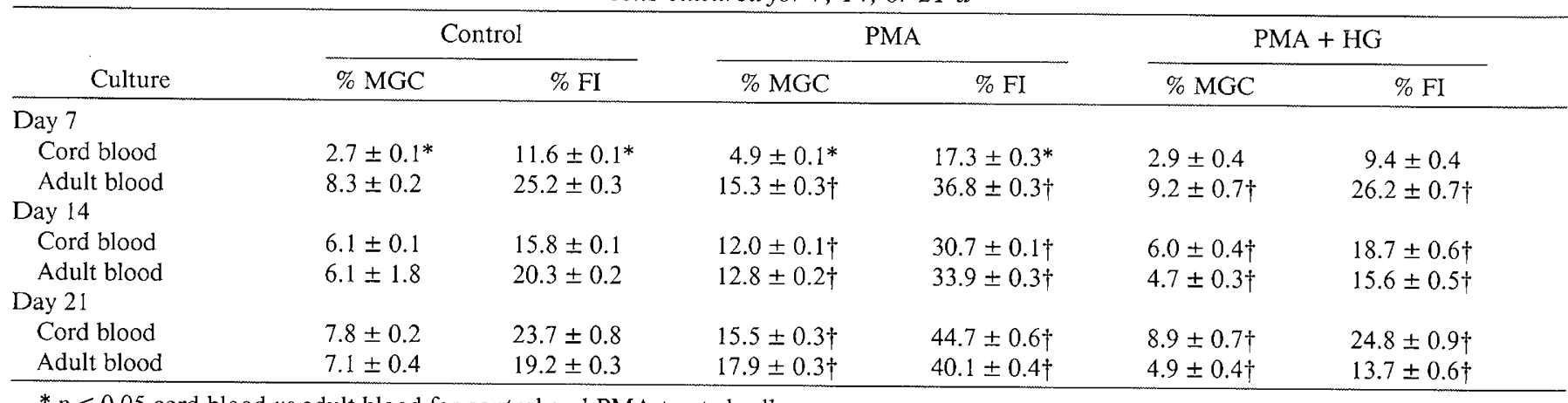

$* p<0.05$ cord blood $v s$ adult blood for control and PMA-treated cells.

$\dagger p<0.05$ PMA-treated $v s$ control cells and HG + PMA vs PMA-treated cells.

fashion in cord blood (Fig. 4) and adult peripheral blood (not shown) 21-d mononuclear cell cultures. Addition of $\mathrm{HG}$ at a concentration of $100 \mu \mathrm{g} / \mathrm{mL}$ significantly decreased PMA-induced MGC formation and the fusion index for both 14- and $21-\mathrm{d}$ cord and adult peripheral blood mononuclear cell cultures (Table 1, Fig. 1). Combined treatment of mononuclear cells with $100 \mu \mathrm{g} / \mathrm{mL} \mathrm{HG}$ and PMA did not significantly inhibit MGC formation or the fusion index below the control values for spontaneous MGC formation in cord blood and adult peripheral blood mononuclear cell cultures (Table 1).

PMA treatment of cord blood and adult peripheral blood mononuclear cell cultures did not result in adherent cell proliferation (Table 2). Proliferating cells were rarely identified on any cord blood and adult peripheral blood mononuclear cell coverslips and never in MGC, but they were readily identifiable on coverslips from cultures of a human leukemic cell line (THP-1). THP-1 cultures exhibited a high percentage of cycling cells that was decreased when the cells were induced to differentiate into mature macrophages with $50 \mathrm{nmol}$ PMA treatment (Table 2).

Pretreatment of cord blood and adult peripheral blood mononuclear cells with $1,25(\mathrm{OH})_{2} \mathrm{D}_{3}$ for $21 \mathrm{~d}$ before PMA exposure significantly inhibited MGC formation and the fusion index (Fig. 5). Treatment of cord or adult peripheral blood mononuclear cells with $1,25(\mathrm{OH})_{2} \mathrm{D}_{3}$ alone for $21 \mathrm{~d}$ had no effect on MGC formation or the fusion index (Fig. 5) compared with control cultures. Pretreatment of monocyte-derived macrophages (isolated from cord and adult peripheral blood by adherence to gelatin-coated plates) with $1,25(\mathrm{OH})_{2} \mathrm{D}_{3}$ alone did not induce MGC formation or increase the fusion index (Fig. 5) but did significantly inhibit PMA-induced MGC formation and the fusion index in cultures of adult peripheral blood-derived cells. In contrast, cord blood monocyte-derived macrophages pretreated with $1,25(\mathrm{OH})_{2} \mathrm{D}_{3}$ were significantly induced to form MGC, and a significant increase in the fusion index (Fig. 5) was observed in the presence of PMA.

PMA-induced MGC formation from the mononuclear cultures was not dependent upon physical coculture of the nonadherent (primarily lymphocyte) and adherent (primarily monocyte-derived macrophage) cell populations. If the nonadherent cells (cord or adult peripheral blood) were cultured in culture plate inserts (separated from the adherent macrophages by a $0.2-\mu \mathrm{m}$ filter) for $21 \mathrm{~d}$ and then treated with PMA, the percentage of MGC formed and fusion index (Fig. 6) were equivalent to results when the nonadherent and adherent cells were cultured together. If monocyte-derived macrophages (cord or adult peripheral blood) were grown for $21 \mathrm{~d}$ in the absence of nonadherent cells however, PMA stimulation only modestly increased the percentage of MGC formed and the fusion index (Fig. 6) to values that were not statistically different from control. In contrast, both the percentage of MGC formed and the fusion index were increased more than 2-fold when monocyte-derived macrophages were treated with PMA in the physical presence of nonadherent mononuclear cells or conditioned media of PMAtreated nonadherent mononuclear cells (Fig. 6).

\section{DISCUSSION}

MGC formation in umbilical cord blood mononuclear cell cultures was first reported as a phenomenon that developed only in aged (3- to 6-wk-old) cultures (17). The MGC formed in those and aged cultures of adult peripheral blood mononuclear cells became less adherent and detached from the plate, and MGC formation heralded cell degeneration in all cultures. MGC were observed to develop sooner in the cultures of cells derived from adult rather than cord blood. Because of the morphologic appearance of the MGC, a cytopathologic viral agent was suspected but never proven as the factor inducing macrophage fusion.

The present report constitutes the first comparative analysis of experimentally induced MGC fusion from mononuclear phagocytes isolated from human cord and adult peripheral blood. Spontaneous MGC formation occurred in both cord and adult blood mononuclear cell populations within 1 wk of culture, although significantly fewer cord blood macrophages fused into MGC. PMA treatment of mononuclear cells from adult blood resulted in a significant increase in MGC formation at all time points studied $(7,14$, or $21 \mathrm{~d})$, but a similar response to PMA was not observed for cord blood mononuclear cells until the 2 nd wk of culture. There was no evidence of PMA stimulating mononuclear cell or MGC proliferation, and thus the MGC formed were indeed the result of cell fusion and not nuclear division without cytokinesis. Both cord and adult blood mononuclear cell populations responded to $1,25(\mathrm{OH})_{2} \mathrm{D}_{3}$ pretreatment by a reduction in PMA-induced MGC formation. Surprisingly, PMA-induced MGC formation was singularly increased after $1,25(\mathrm{OH})_{2} \mathrm{D}_{3}$ pretreatment in nonadherent cell-depleted cultures of cord blood monocyte-derived macrophages. These data indicate that distinct differences exist between macrophages isolated from cord blood versus adult peripheral blood with respect to maturation and achievement of an activated state in response to soluble agents known to induce MGC formation in vitro.

Fusion of macrophages into MGC may spontaneously occur as a final step in macrophage maturation or as a result of in vivo or in vitro exposure to a variety of fusion-promoting agents (5-12). A few MGC normally appear in cultures of human monocyte-derived macrophages, but the percentage of MGC can be increased by adding high concentrations $(0.20)$ of heat-inactivated autologous human serum (18), culturing the cells for prolonged time periods, and assuring that the macrophages can adhere to some surface during maturation $(3,4,17)$. We observed MGC spontaneously developing in cultures of mononuclear cells isolated from both cord and adult peripheral blood. It is unclear why significantly fewer cord-derived than adult blood-derived MGC were formed at the end of the 1 st wk of culture. There 

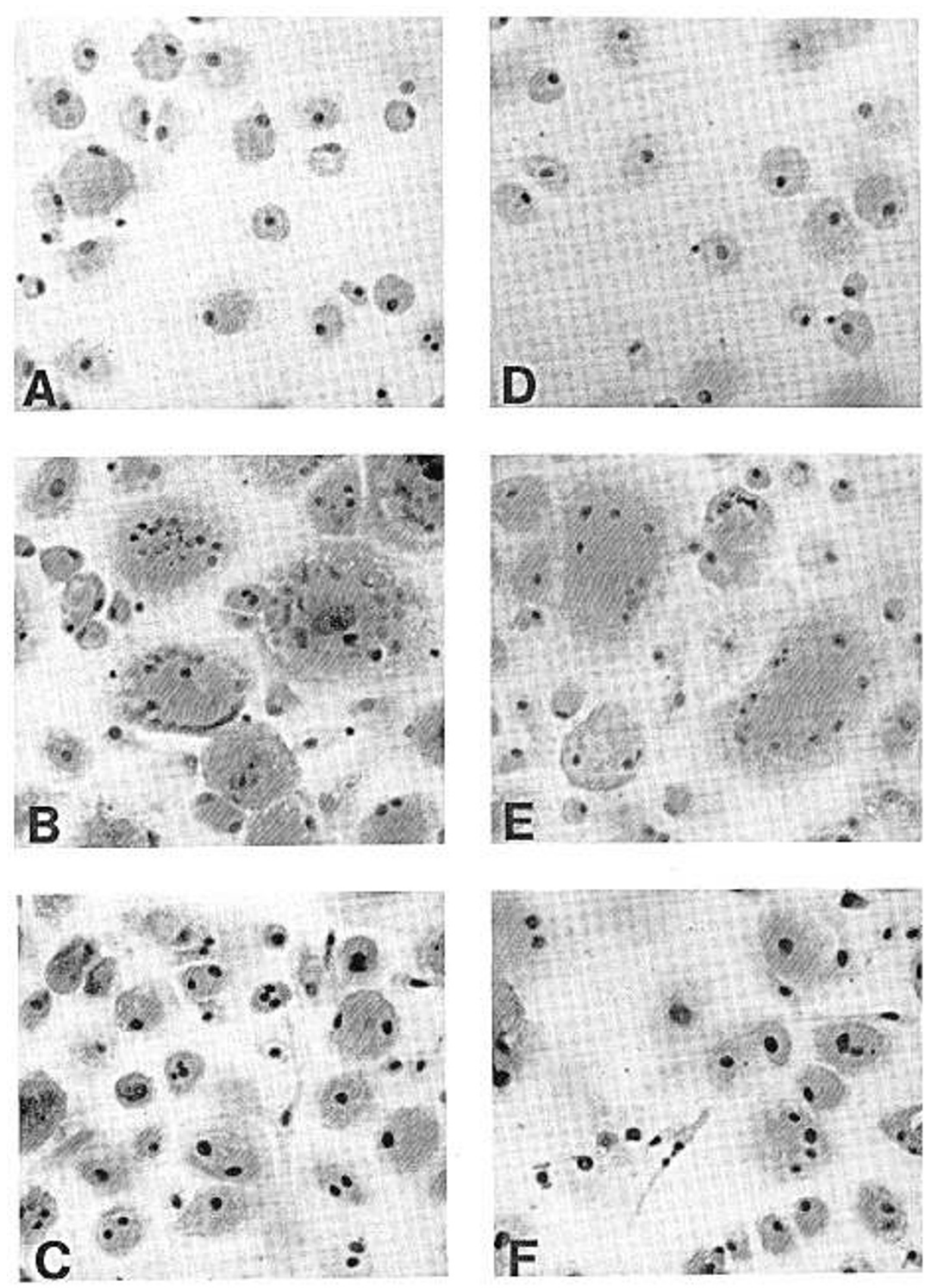

Fig. 1. Adherent macrophage morphology $(\times 400)$ in $21-\mathrm{d}$ cultures of adult $(A)$ and cord blood $(D)$ mononuclear cells. PMA (50 nmol) treatment induced MGC formation in 21 -d cultures of adult $(B)$ and cord blood $(E)$ mononuclear cells. Cotreatment of the 21-d cultures of adult $(C)$ and cord blood $(F)$ mononuclear cells with the protein kinase C inhibitor $\mathrm{HG}(100 \mu \mathrm{g} / \mathrm{mL})$ and PMA $(50 \mathrm{nmol})$ resulted in a significant inhibition of PMA-induced MGC formation.

were no differences noted in the morphologic appearance, expression of esterase and phosphatase activities, density, or viability of the adherent macrophage monolayers when comparing cordand adult blood-derived cells. Because coculture of adult mononuclear cells with the cord cells failed to increase MGC formation in the cord cultures, it is unlikely that the inability of cord bloodderived macrophages to fuse is related to a deficiency in a soluble maturational factor. Similarly, the failure of cord blood mononuclear cells to influence the spontaneous formation of MGC in adult blood mononuclear cell cultures indicates that there are no soluble factors secreted by cord blood mononuclear cells that inhibit MGC formation. The data imply an inherent difference in the normal maturational sequence leading to spontaneous MGC formation in cultures of cord blood monocyte-derived macrophages compared with adult monocyte-derived macrophages.
A number of soluble factors have been demonstrated to induce macrophage fusion in vitro. Osteotropic hormones and factors such as parathyroid hormone, transforming growth factor- $\alpha$, epidermal growth factor, and IL-1 stimulate and calcitonin inhibits MGC formation in vitro from human bone marrow but not peripheral blood mononuclear cells (10). The biologically active form of vitamin $\mathrm{D}_{3}, 1,25(\mathrm{OH})_{2} \mathrm{D}_{3}$, promotes MGC formation from adult human peripheral blood mononuclear cells when these cells are cultured at high density (10) and is a potent in vitro stimulator of murine alveolar macrophage fusion (12). IL-4 promotes MGC formation in mice but inhibits human macrophage MGC formation (9). Mitogen-stimulated lymphocytes secrete numerous soluble factors that stimulate human and murine macrophages to fuse in vitro (11). GM-CSF, IL-6, and IL-3 account for the majority, but not all, of the fusion-promoting activity secreted by the mitogen-stimulated mononuclear 


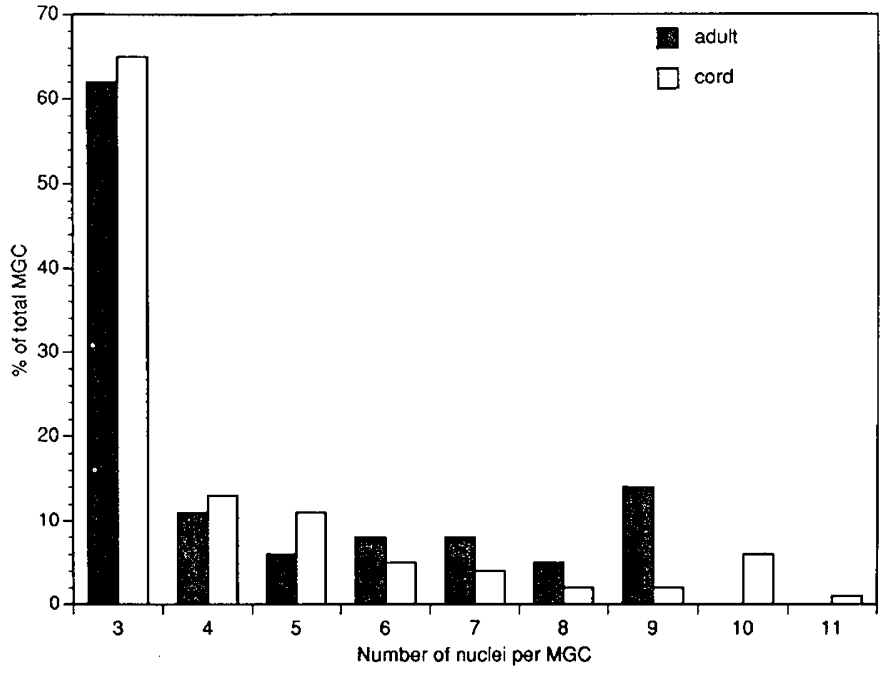

Fig. 2. Distribution of the number of nuclei per MGC formed from adult and cord blood mononuclear cells cultured for $21 \mathrm{~d}$ under control conditions.

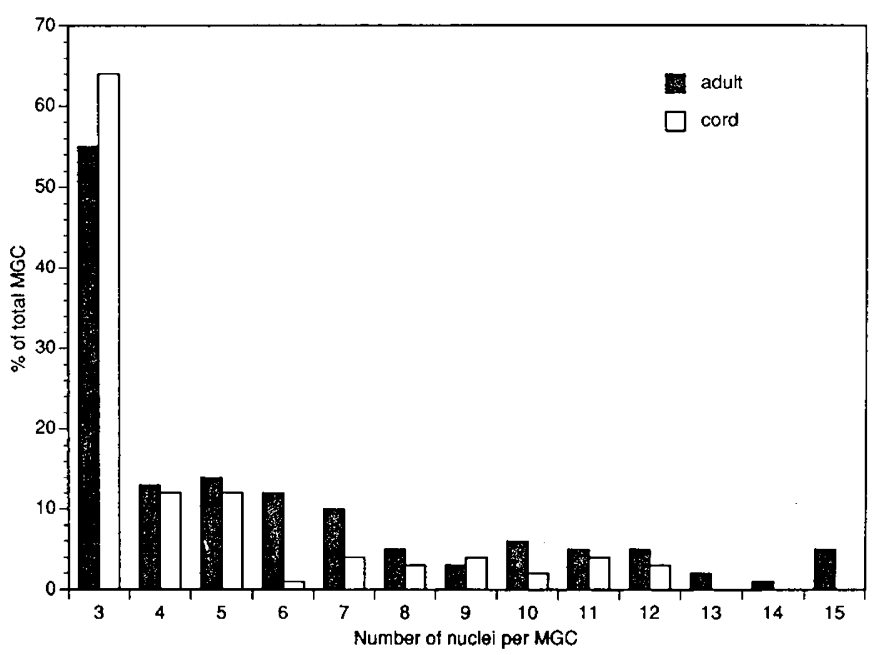

Fig. 3. Distribution of the number of nuclei per MGC formed from adult and cord blood mononuclear cells cultured for $21 \mathrm{~d}$ and then treated with PMA (50 nmol).

cells (19). Interferon- $\gamma$ serves as a pivotal cofactor in inducing macrophage fusion in vitro as it synergizes with several cytokines (GM-CSF, IL-3, and IL-6), retinoic acid, and PMA to stimulate MGC formation (7-9). PMA alone has been demonstrated to induce MGC formation in human monocyte cultures (7). The specific mechanisms through which these soluble cytokines and hormones act to cause macrophage fusion remain poorly understood.

Because PMA can substitute for other agents as a lymphocyte mitogen (20) and PMA alone is sufficient to induce MGC formation, we hypothesized that PMA stimulation of mononuclear cells (lymphocytes plus monocytes) would result in significantly greater MGC formation than PMA stimulation of isolated monocyte-derived macrophages. Indeed, the percentage of MGC formed and the fusion index of PMA-stimulated mononuclear cells (cord or adult derived) were significantly greater than those of companion cultures in which isolated monocytederived macrophages were treated with PMA alone (Figs. 5 and 6). It is unclear why PMA alone failed to significantly induce MGC from the adult blood monocyte-derived macrophages as previously reported by Hassan et al. (7). They reported a fusion index varying from $\sim 55-85 \%$ when adult peripheral blood monocyte-derived macrophages were treated with $50 \mathrm{nmol}$ PMA. We report a fusion index $\sim 25-30 \%$ for similarly treated monocytederived macrophages. Some of the differences in our study results may be accounted for by our use of a different tissue culture media and glass rather than treated plastic coverslips. The culture media used in our experiments contained a lower calcium concentration, and high extracellular calcium concentrations are reportedly an important factor in facilitating the process of macrophage fusion (12). The plastic coverslips used in the experiments of Hassan et al. (7) may have served as a better adhesive substrate than the glass coverslips used in our experiments; macrophage adhesion to a surface is necessary for macrophage fusion to occur no matter what fusion-promoting stimulus is used $(3,4,18,21)$.

The failure of cord blood mononuclear cells to respond to PMA with an increase in MGC at $7 \mathrm{~d}$ of culture suggests a deficiency in the response of cord blood monocyte-derived macrophages to fusion-promoting factors or a deficiency in production of soluble fusion-promoting factors by the cord blood mononuclear cells. Exposure of the cord blood cells with soluble factors secreted from the cocultured adult mononuclear cells did not influence the fusion of cord blood monocyte-derived macrophages and implies that at 7 of in vitro culture, cord blood monocyte-derived macrophages are deficient in responding to fusion-promoting factors. Older cultures of cord blood mononuclear cells responded equally well to PMA as compared with adult blood mononuclear cells, suggesting that the cord blood monocyte-derived macrophages become more responsive to fusion-promoting factors as they mature in vitro. We speculate that the diminished response of the cord blood mononuclear phagocytes to fusion-promoting factors may be related to decreased cell-surface receptors for the fusion-promoting cytokines secreted by mitogen-activated lymphocytes, impaired signal transduction
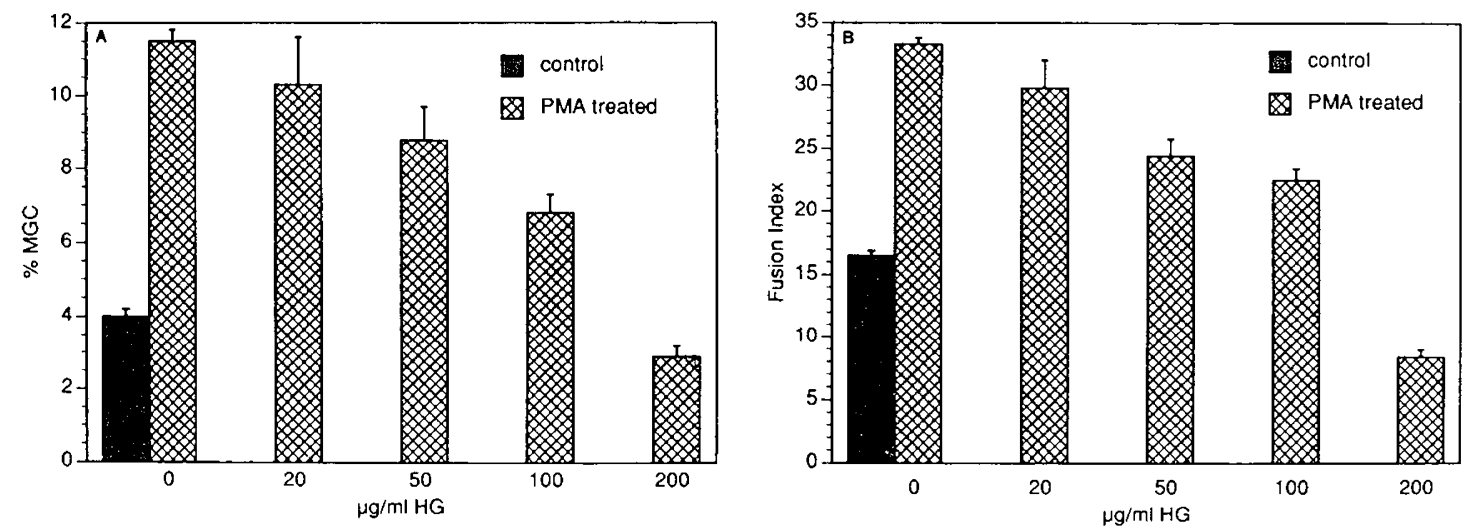

Fig. 4. $A$, MGC formed (\%) and $B$, fusion index of cord blood mononuclear cells cultured for $21 \mathrm{~d}$ and then treated with $0.001 \mathrm{DMSO}$ (control, solid bar) or cotreated with PMA ( $50 \mathrm{nmol}$, cross-hatched bars) and varying concentrations of the protein kinase $\mathrm{C}$ inhibitor $\mathrm{HG}(0-200 \mu \mathrm{g} / \mathrm{mL})$. 
Table 2. Effects of PMA on adherent mononuclear cell proliferation in cord blood, adult peripheral blood, and human leukemic THP-1 cultures listed as \% of total adherent cells that incorporated 5-bromo-2'-deoxyuridine

\begin{tabular}{lcc}
\hline \multirow{1}{*}{ Culture } & \multicolumn{2}{c}{$\%$ Nuclear staining* } \\
\cline { 2 - 3 } & \multicolumn{1}{c}{ Control } & PMA treated \\
\hline Cord blood mononuclear cells & $1.2+0.4$ & $1.7+0.6$ \\
Adult blood mononuclear cells & $0.8+0.5$ & $0.8+0.7$ \\
THP-1 cells & $26.9+1.2$ & $3.3+2.6$ \\
\hline
\end{tabular}

* Values are mean $\pm \mathrm{SD}$.

after cell-surface receptor binding of the cytokines, or an altered intracellular response to protein kinase $\mathrm{C}$ binding of PMA. Comparison of cell-surface binding of GM-CSF, IL-3, and IL-6 to mononuclear phagocytes isolated from cord or adult blood would address the first question. The precise cascade of intracellular events initiated by GM-CSF, IL-3, and IL-6 after binding to the cell-surface of mononuclear phagocytes remain poorly understood but include changes in protein phosphorylation, activation of protein kinase $\mathrm{C}$, and altered intracellular concentrations of cyclic nucleotides (9). Examination of these transduction pathways may also suggest inherent differences in the re- sponse of cord blood compared with adult peripheral blood mononuclear phagocytes.

The critical role of protein kinase $\mathrm{C}$ in mediating the PMA effect was demonstrated by the complete inhibition of MGC formation in the cord- or adult blood-derived cultures when the protein kinase $\mathrm{C}$ inhibitor $\mathrm{HG}$ was added to PMA-treated mononuclear cells. Other investigators have noted the importance of protein kinase $\mathrm{C}$ and both intracellular and extracellular calcium concentrations in mediating PMA-induced MGC formation from adult peripheral blood monocytes and monocyte-derived macrophages $(21,22)$. We observed no difference in the ability of $\mathrm{HG}$ to inhibit PMA-induced MGC formation in mononuclear cells isolated from cord or adult blood, thus ruling out a significant difference in protein kinase $\mathrm{C}$ concentration and its function as a primary cause for the difference in behavior of the cord and adult blood mononuclear cells.

$1,25(\mathrm{OH})_{2} \mathrm{D}_{3}$ has been reported to stimulate MGC formation from human peripheral blood mononuclear cells and induce osteoclast (bone marrow MGC with the capacity to resorb bone) formation from human bone marrow mononuclear cells (10). We hypothesized that $1,25(\mathrm{OH})_{2} \mathrm{D}_{3}$ would synergize with PMA in stimulating MGC from cord blood and adult peripheral blood mononuclear cells because $1,25(\mathrm{OH})_{2} \mathrm{D}_{3}$ may also induce MGC through a calcium-dependent mechanism (12). We report that
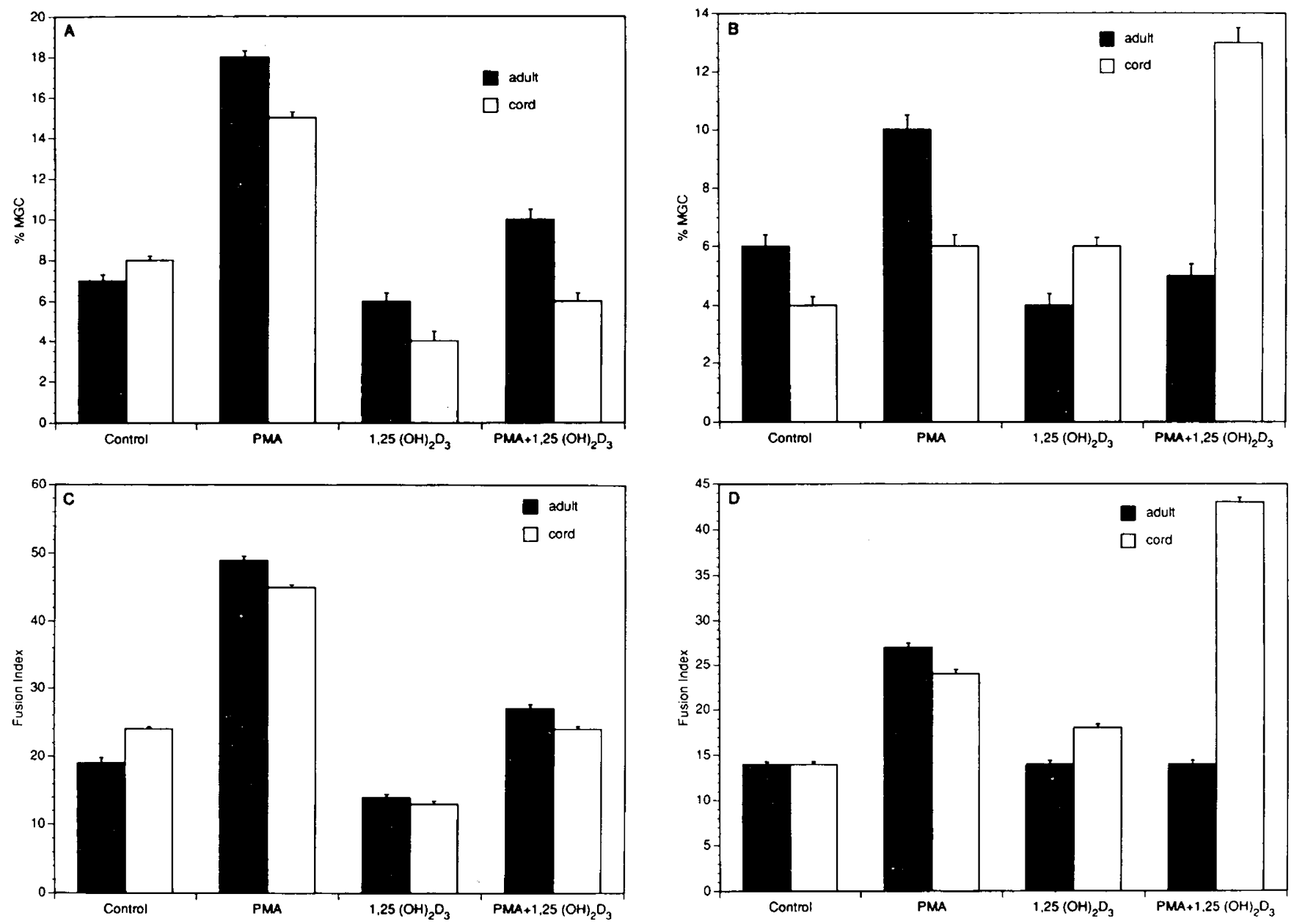

Fig. 5. Adult (solid bar) and cord blood (open bar) mononuclear cells $(A$ and $C$ ) or monocyte-derived macrophages $(B$ and $D)$ were cultured for $21 \mathrm{~d}$ before $16 \mathrm{~h}$ of 0.001 DMSO (control group) or $50 \mathrm{nmol}$ PMA treatment (PMA group), or the mononuclear cells and monocyte-derived macrophages were cultured for $21 \mathrm{~d}$ in $1,25(\mathrm{OH})_{2} \mathrm{D}_{3}\left(10^{-8} \mathrm{M}\right)$ before 0.001 DMSO $\left(1,25(\mathrm{OH})_{2} \mathrm{D}_{3}\right.$ group $)$ or 50 nmol PMA treatment $[\mathrm{PMA}+$ $1,25(\mathrm{OH})_{2} \mathrm{D}_{3}$ group]. Data are presented as the \% MGC formed $(A$ and $B)$ or fusion index $(C$ and $D)$. $p<0.05$ PMA vs control (both cord and adult cells in $A$ and $C$ ) and PMA $+1,25(\mathrm{OH})_{2} \mathrm{D}_{3}$ vs PMA (both cord and adult cells in $A$ and $C$ ). $p<0.05$ PMA $+1,25(\mathrm{OH})_{2} \mathrm{D}_{3}$ vs control, PMA, or $1,25(\mathrm{OH})_{2} \mathrm{D}_{3}$ (cord cells in $B$ and $D$ ). 

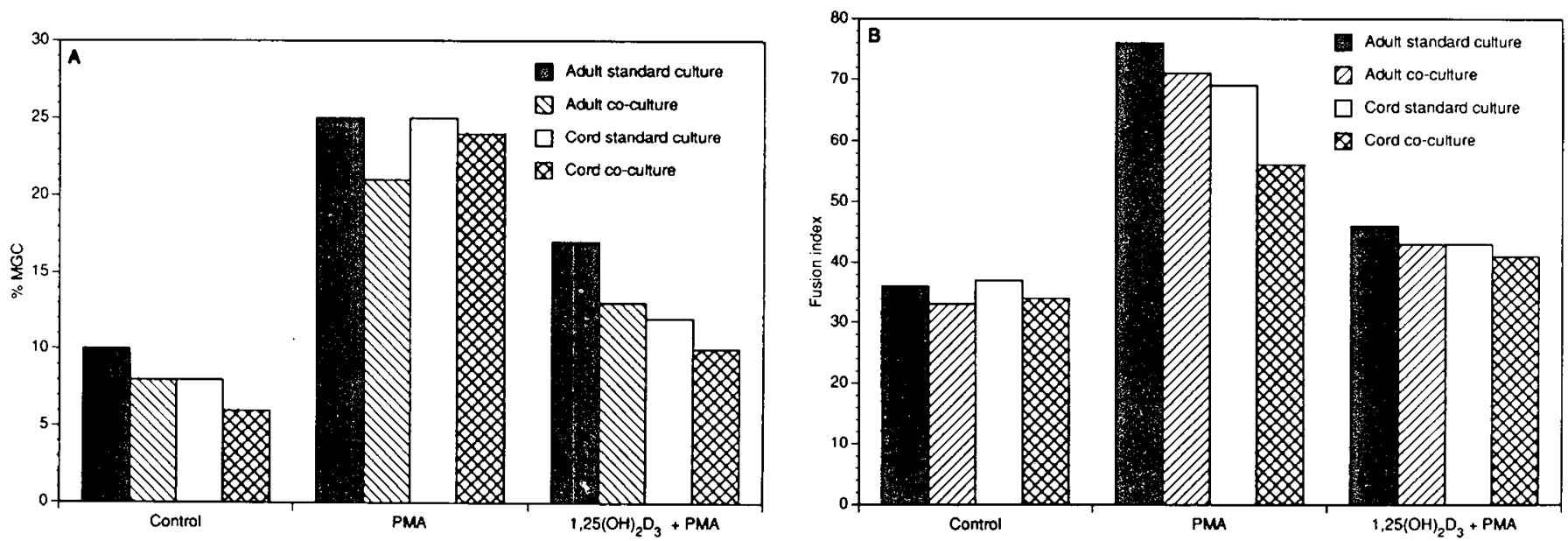

Fig. 6. Adult (adult standard culture, solid bars) and cord blood (cord standard culture, open bars) mononuclear cells were cultured for $21 \mathrm{~d}$ before 0.001 DMSO (control group) or $50 \mathrm{nmol}$ PMA treatment (PMA group) or were cultured for $21 \mathrm{~d}$ in the presence of $1,25(\mathrm{OH})_{2} \mathrm{D}_{3}\left(10^{-8} \mathrm{M}\right.$ ) before 50-nmol PMA treatment $\left[1,25(\mathrm{OH})_{2} \mathrm{D}_{3}+\right.$ PMA group]. Coculture experiments were performed in which adult (adult coculture, hatched bars) or cord (cord coculture, cross-hatched bars) nonadherent mononuclear cells were suspended in culture plate inserts above adherent monocytederived macrophages and treated as above. Data are presented as the \% MGC formed $(A)$ or fusion index $(B)$.

$10^{-8} \mathrm{M} 1,25(\mathrm{OH})_{2} \mathrm{D}_{3}$ alone failed to induce macrophage fusion and significantly inhibited MGC formation when either cord blood or adult blood mononuclear cells were prestimulated for $21 \mathrm{~d}$ with the vitamin and then treated with PMA. In the report by Takahashi et al. (10), MGC were enumerated as the total number of $\mathrm{MGC}$ formed from 1 million mononuclear cells. In their study, approximately $250 \mathrm{MGC} / 1 \times 10^{6}$ mononuclear cells were formed after $21 \mathrm{~d}$ of culture in the presence of $10^{-8} \mathrm{M}$ $1,25(\mathrm{OH})_{2} \mathrm{D}_{3}$ compared with $<10 \mathrm{MGC} / 1 \times 10^{6}$ mononuclear cells in control cultures. It is difficult to compare our results with those of Takahashi et al. (10), not only because we reported our data as a percentage of total macrophages (600) counted, but also because we used a different concentration and source of serum and we cultured the mononuclear cells on glass coverslips and not tissue-culture plastic. As noted above, the source and concentration of serum and substrate to which macrophages attach are known to directly influence the formation of MGC $(3,4,18,21)$. Nevertheless, if we assume previously published data $(23,24)$ that only $\sim 25 \%$ of the initial number of human adherent monocyte macrophages plated survive in vitro for $21 \mathrm{~d}$, we estimate that $280 \mathrm{MGC}$ were formed per $1 \times 10^{6}$ adult mononuclear cells cultured under control conditions and 240 MGC/ $1 \times 10^{6}$ cells were formed in $1,25(\mathrm{OH})_{2} \mathrm{D}_{3}$ treated adult blood-derived mononuclear cell cultures in our study (data derived from Fig. 5). Apparently, our culture conditions resulted in significantly higher spontaneous MGC formation, and either the mononuclear cells did not respond to the concentration of $1,25(\mathrm{OH})_{2} \mathrm{D}_{3}$ that we administered or the effects of this vitamin were influenced by the presence of other fusion-promoting factors present in the human serum. The ability of $1,25(\mathrm{OH})_{2} \mathrm{D}_{3}$ to completely inhibit PMA-induced MGC formation in both cord and adult blood mononuclear cell cultures indicates that some of the cells were quite responsive and suggests that $10^{-8} \mathrm{M}$ $1,25(\mathrm{OH})_{2} \mathrm{D}_{3}$ alone is inadequate to induce $\mathrm{MGC}$ formation in our culture conditions.

$1,25(\mathrm{OH})_{2} \mathrm{D}_{3}$ can modulate both monocyte-macrophage and lymphocyte function in vivo and in vitro (25). Because monocytes and macrophages constitutively express the receptor for $1,25(\mathrm{OH})_{2} \mathrm{D}_{3}$ but lymphocytes require some form of activation to express the receptor (25), the inhibition of PMA-induced MGC formation from cord and adult mononuclear cells by $1,25(\mathrm{OH})_{2} \mathrm{D}_{3}$ must involve a complex interplay between $1,25(\mathrm{OH})_{2} \mathrm{D}_{3}$ prestimulated macrophages and PMA-responsive lymphocytes. $1,25(\mathrm{OH})_{2} \mathrm{D}_{3}$ can inhibit macrophage secretion of cytokines (IL-1 $\alpha$, IL-6) that are not only important in lymphocyte proliferative and secretory behavior (26) but also stimulate
MGC formation. Additional studies will be required to elucidate how $1,25(\mathrm{OH})_{2} \mathrm{D}_{3}$ inhibits PMA-induced MGC formation from mononuclear cells and to determine if $1,25(\mathrm{OH})_{2} \mathrm{D}_{3}$ may influence the MGC-inducing effects of other soluble cytokines.

$1,25(\mathrm{OH})_{2} \mathrm{D}_{3}$ prestimulation of cord blood monocyte-derived macrophages was associated with significant PMA-induced MGC formation. This effect of $1,25(\mathrm{OH})_{2} \mathrm{D}_{3}$ and PMA was not observed in the cultures of adult peripheral blood monocyte-derived macrophages. One possible explanation for these results is that cord blood contains a monocyte precursor for osteoclasts (27) and adult peripheral blood does not (10). Osteoclast precursors are highly responsive to $1,25(\mathrm{OH})_{2} \mathrm{D}_{3}$ and readily fuse in vitro in the presence of this vitamin in cooperation with secondary factors $(27,28)$. It remains unclear what the secondary factors are that are required for $1,25(\mathrm{OH})_{2} \mathrm{D}_{3}$ to induce osteoclast precursors to form osteoclasts. We speculate that PMA may be serving as one such secondary factor because PMA has been demonstrated to increase vitamin $\mathrm{D}$ receptor number in myeloid tumor cells and lymphocytes $(29,30)$.

We did not determine whether the MGC formed in our experiments from the cord blood monocyte-derived macrophages are in fact osteoclast precursors. Because there are no unique distinguishing features of osteoclast precursors, it remains impossible to positively identify these cells from other mononuclear phagocytes (27). Currently, few reliable markers of osteoclast differentiation exist. We did confirm the expression of tartrate-resistant acid phosphatase activity by the MGC. However, tartrate-resistant acid-phosphatase expression is a feature of several mature mononuclear phagocyte subsets and is no longer considered an exclusive feature of osteoclasts (28). Regulation of osteoclast function by calcitonin through a cell-surface calcitonin receptor is a distinct marker of mature osteoclasts (31). The recent cloning of this receptor should allow for specific identification of osteoclast formation in vitro and may help identify the precursor cells in future experiments (28).

It is interesting that PMA-induced MGC appeared in $1,25(\mathrm{OH})_{2} \mathrm{D}_{3}$ pretreated 3-wk-old cultures of cord blood monocyte-derived macrophages only in the absence of lymphocytes. Apparently, lymphocytes play a significant role in determining how monocyte-derived macrophages respond to $1,25(\mathrm{OH})_{2} \mathrm{D}_{3}$ in vitro. Additional studies of how $1,25(\mathrm{OH})_{2} \mathrm{D}_{3}$ regulates differentiation and function of monocytes including potential osteoclast precursor cells present in cord blood and the role of lymphocytes in modulating these effects of the vitamin are needed.

In conclusion, we report that spontaneous and PMA-induced formation of MGC is diminished in early cultures of cord blood 
mononuclear cells compared with adult peripheral blood mononuclear cells. Furthermore, cord blood monocyte-derived macrophages respond to PMA and $1,25(\mathrm{OH})_{2} \mathrm{D}_{3}$ with $\mathrm{MGC}$ formation, whereas monocyte-derived macrophages isolated from adult peripheral blood do not. These data point out some inherent differences in the maturational state of cord blood compared with adult peripheral blood monocyte-derived macrophages. It is unclear whether such differences in monocyte-derived macrophage function persist beyond the time of birth and whether similar differences in function are exhibited by fixed tissue macrophages in situ.

\section{REFERENCES}

1. Wilson CB 1990 Developmental immunology and the role of host defenses in neonatal susceptibility. In: Remington JS, Klein JO (eds) Infectious Diseases of the Fetus and Newborn Infant, 3rd Ed. WB Saunders, Philadelphia, pp 17-67

2. Adams DO 1976 The granulomatous inflammatory response. Am J Pathol 84:164-191

3. Chambers TJ 1978 Multinucleated giant cells. J Pathol 126:125-148

4. Mariano M, Spector WG 1974 The formation and properties of macrophage polykaryons (inflammatory giant cells). J Pathol 113:1-19

5. Johnston Jr RB 1988 Monocytes and macrophages. N Engl J Med 318:747752

6. Shikama Y Kobayashi K, Kasahara K, Kaga S, Hashimoto M, Yoneya I, Hosoda S, Soejima K, Ide H, Takahashi T 1989 Granuloma formation by artificial microparticles in vitro. Macrophages and monokines play a critical role in granuloma formation. Am J Pathol 134:1189-1194

7. Hassan NF, Kamani N, Meszaros MM, Douglas SD 1989 Induction of multinucleated giant cell formation from human blood-derived monocytes by phorbol myristate acetate in in vitro culture. J Immunol 143:2179-2184

8. Weinberg JB, Hobbs MM, Misukonis M 1984 Recombinant human $\gamma$-interferon induces human monocyte polykaryon formation. Proc Natl Acad Sci $81: 4554-4557$

9. Enelow RI, Sullivan GW, Carper HT, Mandell GL 1992 Induction of multinucleated giant cell formation from in vitro culture of human monocytes with interleukin-3 and interferon- $\gamma$ : comparison with other stimulating factors. Am J Respir Cell Mol Biol 6:57-62

10. Takahashi N, Kukita T, MacDonald BR, Bird A, Mundy GR, McManus LM, Miller M, Boyde A, Jones SJ, Roodman GD 1989 Osteoclast-like cells form in long-term human bone marrow but not in peripheral blood cultures. $J$ Clin Invest 83:543-550

11. Postlethwaite AE, Jackson BK, Beachey EH, Kang AH 1982 Formation of multinucleated giant cells from human monocyte precursors. J Exp Med 155:168-178

12. Jin C, Miyaura H, Tanaka H, Takito J, Abe E, Suda T 1990 Fusion of mouse alveolar macrophages induced by $1 \alpha, 25$-dihydroxyvitamin $\mathrm{D}_{3}$ involves extracellular, but not intracellular calcium. J Cell Physiol 142:434-439

13. Yoder MC, Hassan NF, Douglas SD 1992 Mononuclear phagocyte system. In:
Polin RA, Fox WW (eds) Fetal and Neonatal Physiology. WB Saunders, Philadelphia, pp 1438-1460

14. Hassan NF, Campbell DE, Douglas SD 1986 Purification of human monocytes on gelatin-coated surfaces. J Immunol Methods 95:273-276

15. Yoder MC, Lanker TA, Engle WA 1988 Culture medium oxygen tension affects fibronectin production in human adult and cord blood macrophages. Immunol Lett 19:1-6

16. Kramer IM, vanderBend RL, Tool AT, Blitterswijk WJ, Roos D, Verhoven AJ 1989 1-O-hexadecyl-2-O-methylglycerol, a novel inhibitor of protein kinase $\mathrm{C}$, inhibits the respiratory burst in human neutrophils. J Biol Chem 264:5876-5884

17. zur Hausen H, de Villiers E 1982 Syncytium formation in aged umbilical cord blood macrophages. Attempts to demonstrate an infectious etiology. Med Microbiol Immunol 170:229-240

18. Schlesinger L, Musson RA, Johnston Jr, RB 1984 Functional and biochemical studies of multinucleated giant cells derived from the culture of human monocytes. J Exp Med 159:1289-1294

19. Abe E, Ishimi Y, Jin C, Hong MH, Sato T, Suda T 1991 Granulocytemacrophage colony-stimulating factor is a major macrophage fusion factor present in conditioned medium of concanavalin A-stimulated spleen cell cultures. J Immunol 147:1810-1815

20. Truneh A, Albert F, Golstein P, Schmitt-Verhurst A 1985 Early steps of lymphocyte activation bypassed by synergy between calcium ionophores and phorbol ester. Nature 313:318-320

21. Orentas RJ, Reinlab L, Hildreth JEK 1992 Anti-class II MHC antibody induces multinucleated giant cell formation from peripheral blood monocytes. $J$ Leukocyte Biol 51:199-209

22. Kreipe H, Radzun HJ, Rudolph P, Barth J, Hansmann M, Heidorn K, Parwaresch MR 1988 Multinucleated giant cells generated in vitro. Am J Pathol 130:232-243

23. Santiago-Schwarz F, Fleit HB 1988 Identification of nonadherent mononuclear cells in human cord blood that differentiate into macrophages. J Leukocyte Biol 43:51-59

24. Vincent F, Eischen A, Bergerat JP 1992 Human blood-derived macrophages: differentiation in vitro of a large quantity of cells in serum-free medium. Exp Hematol 20:17-23

25. Yoder MC, Manolagas SC 1991 Vitamin D and its role in immune function. Clin Appl Nutr 1:35-44

26. Muller K, Diamant M, Bendtzen K 1991 Inhibition of production and function of interleukin- 6 by 1,25-dihydroxyvitamin $\mathrm{D}_{3}$. Immunol Lett 28:115-120

27. Orcel P, Bielakoff J, De Vernejoul M 1990 Formation of multinucleated cells with osteoclast precursor features in human cord monocyte cultures. Anat $\operatorname{Rec} 226: 1-9$

28. Hattersely G, Chambers TJ 1989 Generation of osteoclasts from hemopoietic cells and a multipotential cell line in vitro. J Cell Physiol 140:478-482

29. Hewison M, Barker S, Brennan A, Katz DR, O'Riordan JLH 1988 Phorbol ester stimulation of $25 \mathrm{OH}$-vitamin D 1-hydroxylase activity in the monoblastic cell line U937. In: Norman AW, Schaefer K, Grigoleit H-G, Herrath $\mathrm{D}$ (eds) Molecular, Cellular and Clinical Endocrinology. deGruyter, Berlin, pp 360-361

30. Yu X-P, Mocharla H, Hustmyer FG, Manolagas SC 1991 Vitamin D receptor expression in human Iymphocytes. J Biol Chem 266:7588-7595

31. Hattersely G, Chambers TJ 1992 Bones need SOFAs. Current Opinion Cell Biol 2:140-14 